\title{
Hemoglobin S/O-Arab Heterozygote
}

National Cancer Institute

\section{Source}

National Cancer Institute. Hemoglobin SIO-Arab Heterozygote. NCI Thesaurus. Code C156899.

\begin{abstract}
A laboratory finding indicating that the subject expresses abnormal hemoglobin containing 2 variant forms of the hemoglobin subunit beta protein (HBB). One HBB protein variant has the amino acid substitution glutamic acid to valine at residue 6 , which is associated with the formation of hemog lobin $\mathrm{S}(\mathrm{HbS})$, while the other variant has a glutamic acid to lysine substitution at residue 121, which is associated with the formation of hemoglobin O-Arab ( $\mathrm{HbO}($ Arab)). Subjects expressing this compound heterozygous HBB genotype may have severe sickling hemoglobinopathy with clinical manifestations similar to those of homozygous sickle cell anemia.
\end{abstract}

